\title{
General Approach to Mechanochemistry and Its Relation to Tribochemistry
}

\author{
Czesław Kajdas
}

Additional information is available at the end of the chapter

http://dx.doi.org/10.5772/50507

\section{Introduction}

\subsection{Compact information on the considered disciplines}

Mechanochemistry and tribochemistry disciplines are of particular importance for fundamental research and tribology engineering practice. They relate to specific coupling of physical and chemical phenomena leading to initiation of heterogeneous chemical reactions due to mechanical action.

Chemical reactions in solids initiated by mechanical action had been considered for a long period of time [1]. From the viewpoint of terms, mechanochemistry and tribochemistry may be compared with terms: physical chemistry and chemical physics. In the latter term physics is first and chemistry second. In tribochemistry, friction (tribos) is the first. Since mechanics includes friction, tribochemistry should be included in mechanochemistry. Reviews on mechanochemistry [2,3] show Matthew Carey Lea as the first systematic researcher on the chemical effects of mechanical action.

Mechanochemical reactions are clearly distinct from those of thermochemical ones. To initiate thermochemical reactions an adequate heat amount has to be supplied to overcome the activation energy.

Mechanical interaction of a solid-solid enables chemical reactions to be initiated by lower activation energy than regular thermochemical reactions.

Even a very high calculated 'flash temperature' is short-lived, thus, it rather cannot initiate chemical reactions by heat. Reference [4] demonstrates that high local temperatures generated by friction at the contacts between rubbing surfaces can evolve thermionic activity, likely to be short lived and random. These localized, dynamic regions of intense thermionic emission can act as catalytic sites for chemical activity. 


\subsection{Definition of mechanochemistry for the present book chapter}

Mechanochemistry is the science field dealing with ultra-fast chemical reactions between solids or solids and surrounding gaseous or liquid molecules under mechanical forces. There are many detailed definitions focused on selected branches of mechanochemistry. Reference [5] defines mechanochemistry as the branch of solid state chemistry where bonds are mechanically broken The bond breakage can induce electron transfers, triboelectricity (known as mechanoelectricity), and triboluminescence. These phenomena are in a branch of mechanophysics. Similarly, thermal expansion, piezoelectric effects, or compression by pressurizing might also be related to mechanophysics; details are discussed in [6].

In this chapter the following general definition, taken from [7-8] has been selected 'Mechanochemistry is a branch of chemistry which is concerned with chemical and physicochemical transformations of substances in all states of aggregation produced by the effect of mechanical energy'. This definition was formulated 50 years ago and is accepted nowadays.

\subsection{Definition of tribochemistry for the present book chapter}

Similarly to mechanochemistry, also tribochemistry relates to mechanically initiated chemistry. The activation energies of tribochemical reactions are lower than those of thermochemical ones. Chemical reactions of tribological additives proceeding during the boundary lubrication (BL) process involve the formation of a film on the contact surface. BL is the condition of lubrication, in which the friction and wear between two surfaces in relative motion are determined by the properties of the surfaces and by the properties of the lubricant other than viscosity. This definition is closely related to the Hardy's first approach to the boundary lubrication process [9]. Campbell [10] emphasizes that BL is perhaps the most confusing and complex aspect of the subject of friction and wear prevention.

Tribochemical reactions are also distinct from those of thermochemical reactions. The same is due to heterogeneous catalysis (HetCat) and tribocatalysis [11]. Principles and applications of HetCat are compiled in [12]. To initiate thermochemical reactions heat should be supplied. There are many definitions of the tribochemistry term. Reference [13] defines tribochemistry as the chemical reactions that occur between the lubricant and the surfaces under BL conditions and stresses that the precise nature of the chemical reactions is not well understood. Book [14] just states that tribochemistry concerns interacting chemical reactions and processes.

The present author proposes to consider tribochemistry as a subset of mechanochemistry and thus, for this book chapter the following general definition 'Tribochemistry is a branch of chemistry dealing with the chemical and physico-chemical changes of solids due to the influence of mechanical energy', has been selected [7-8]. 


\section{Flash temperature vs. thermionic emission}

\subsection{Frictional thermal energy}

The input of thermal energy generated in a tribological system of boundary friction is lower than the output. Thus, it seems convenient to consider heat evolution also in electronic terms. Not considering any heat loss, the difference is controlled by energy stored in the system. Looking at the mechanical work plane proposed in [15], various portions of the work (power) include: input power, use-output power, loss-output energy rate, and a stored energy (thermal energy transformed from mechanical work). The energy stored (excess energy) points on the origin of enhanced reactivity of solids.

Mechanochemical reactions constitute a complex multistage process, which include stages involving mechanical deformation of a substance (the supply and absorption of mechanical energy), the primary chemical reactions, and different secondary processes [16]. It should be noted that higher reactivity of solids is of particular importance from the view-point of engineering aspects.

\subsection{Brief information on the 'flash temperature' term}

The temperature rise at the peaks of the contacting asperities can be high but their duration is very short. The high order of magnitude and very short duration is due to the tiny area of contact [17]. Flash temperature is a means of accounting for the local frictional heat flux. Details related to flash temperature till 1990 are summarized in [18].

Reference [19] reviewing the present literature on flash temperature, demonstrates that for low-speed sliding, thermal effects on tribochemical reactions are negligible. Attempts to measure the contact temperature at very low sliding velocities in fretting [20], show low temperature increases and, they are well corroborated by results of theoretical calculations.

An early publication by Archard [21] deals with temperatures evolved by friction. The second part of reference [22] is on temperature distributions of friction bodies. Critical assessment of the flash-temperature concept has been presented in work [23]. It is of note at this point that frictionally generated high local temperatures can also be reflected as the thermionic emission [4].

Summarizing this information, it can be said that the flash temperature term relates to the maximum local temperature generated in a sliding contact. It occurs at areas of real contact due to the frictional heat dissipated at these spots. Theoretical study on frictional temperature rises and the flash temperature concept are assigned to Blok [24, 25] and continued by other researchers, eg. [21,23,26-27].

\subsection{Thermionic emission}

Work [28] shows that when the friction contact takes place at the tip of the contacting asperities, local temperatures reach significant values even in the very small time interval of 
$3 \mathrm{~ms}$. Recent publication [29] stresses that the maximum temperature reached at a single asperity contacts corresponds to the flash temperature. As there may be many asperity contacts of different size interacting at once, there should be a distribution of such temperatures. Reference [28] also demonstrates that the high flash temperatures occur even while the overall temperature rise of the surface may be much lower. This information leads to a linkage of triboemission with flash temperature.

Now we need to come back to the present author's suggestion that flash temperature, expressed as the maximum computed friction temperature, can also be considered in terms of the thermionic emission [29]. Thereafter, flash temperatures might be expressed in the form of electronic energy. Most recently, that assumption was confirmed by examining of thermionic emission due to frictionally generated heat. The emission of electrons from a surface due to heating was investigated theoretically for sliding contacts [4]. A thermal model previously developed by Vick and Furey [30-31] for sliding contact was used to predict the temperature rise over the surface and the Richardson-Dushman equation for thermionic emission was then used to estimate the corresponding current density from the surface. The computed results demonstrate that high local temperatures generated by friction of the contacts between rubbing surfaces can activate the emission of electrons (see Figure 1). The temperature increase in Figure 1 is observable over both the actual contact area and a region immediately downstream of the contact due to energy convected by the motion of the material. The maximum temperature rise is $1003 \mathrm{~K}$ and the thermionic current density increase has a severe peak in the neighborhood of the maximum temperature and is almost unnoticeable elsewhere.
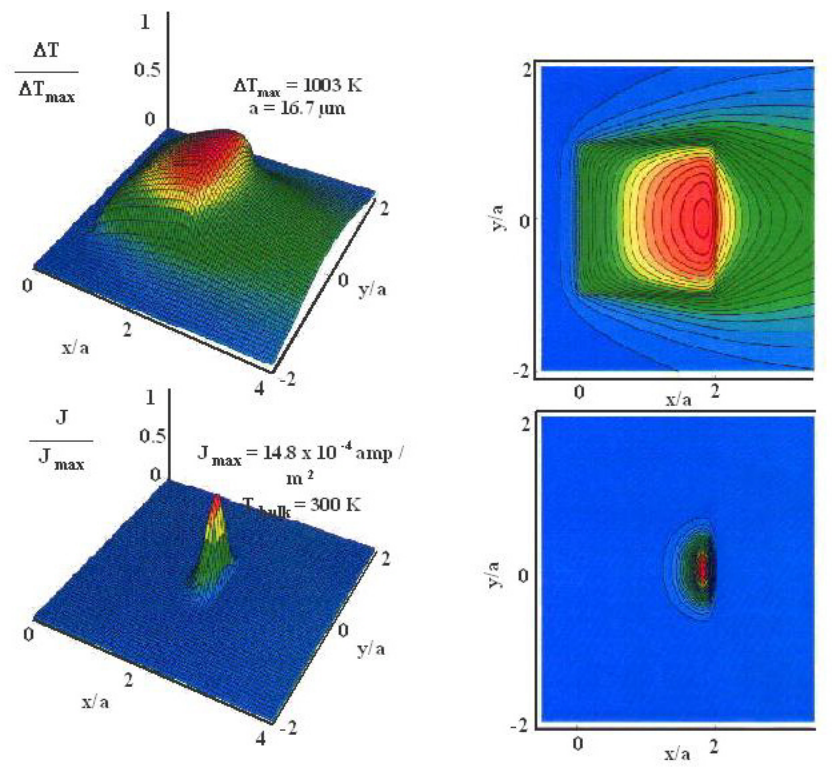

Figure 1. Normalized temperature distribution and corresponding current density from the surface of iron for an applied load of $F=1 \mathrm{~N}$, sliding speed of $V=10 \mathrm{~m} / \mathrm{s}$ and coefficient of friction of 1 [4]. 
This is a result of the strong exponential nonlinear relationship between absolute temperature and current density. It is evidenced by results shown in Figure 2, displaying the effect of increasing velocity or load over the narrow range of parameters. This effect is due to the strong nonlinearity and sensitivity between current density and temperature.
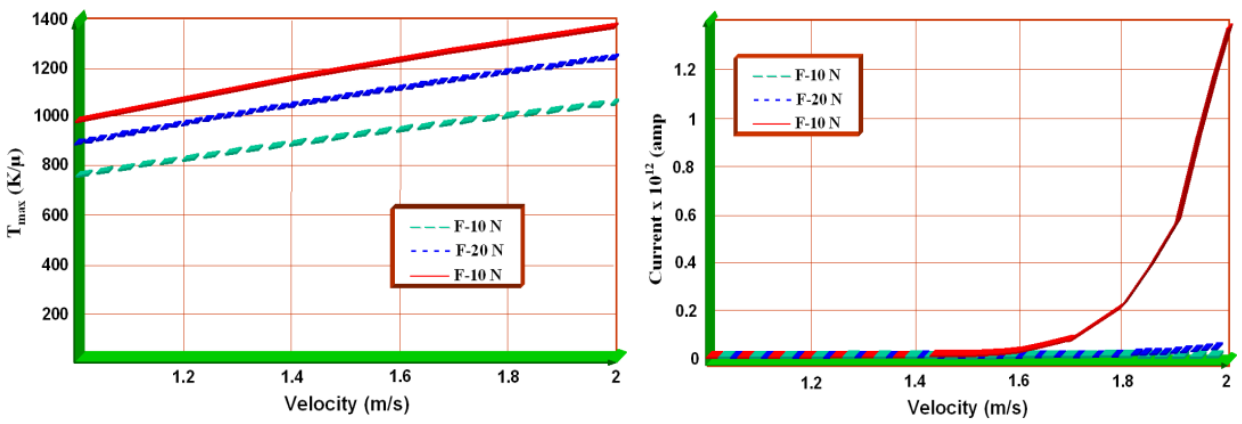

Figure 2. Effect of velocity and load on the maximum temperature divided by friction coefficient and total current from the surface of iron [4].

Two decades back tribo-stimulated and photo-stimulated exoelectron emission (TSEE, PSEE) from reactor graphite was investigated, because an increase in TSEE from graphite was due to high friction. Selective deformation of graphite fibrils was identified with transmission electron microscopy [32] and it was found that the exothermic process during the preferred orientation caused emission of tribo-stimulated electrons. PSEE from reactor graphite was also detected. New surface analysis method using TSEE has been developed to estimate the ability for metals in practical use to emit electrons. This method uses an exoelectron emission phenomenon observed only while metal surfaces are mechanically rubbed with a PTFE (polytetrafluoroethylene) rotator. Number of electrons emitted from copper and iron metals during rubbing was measured using a newly hand-made electron counting device [33]. The relationship of emitted electrons to the XPS (x-ray photoelectron spectroscopy) results of the metal surfaces also was investigated.

Thermionic emission due to frictionally generated temperatures in sliding contact can have a number of important consequences, including activation of tribochemical reactions according to the NIRAM approach and enhancement of surface reactivity [4]. Therefore similarly to the typical TSEE, generated in the sliding contact, thermionic emission (eth), can be combined with the NIRAM approach in terms of enhancement of surface activity as demonstrated in Figure 3 [29].

Accordding to the NIRAM approach tribochemical reactions are initiated by both tribo (e) and thermionic (eth) electrons of low-energy. 


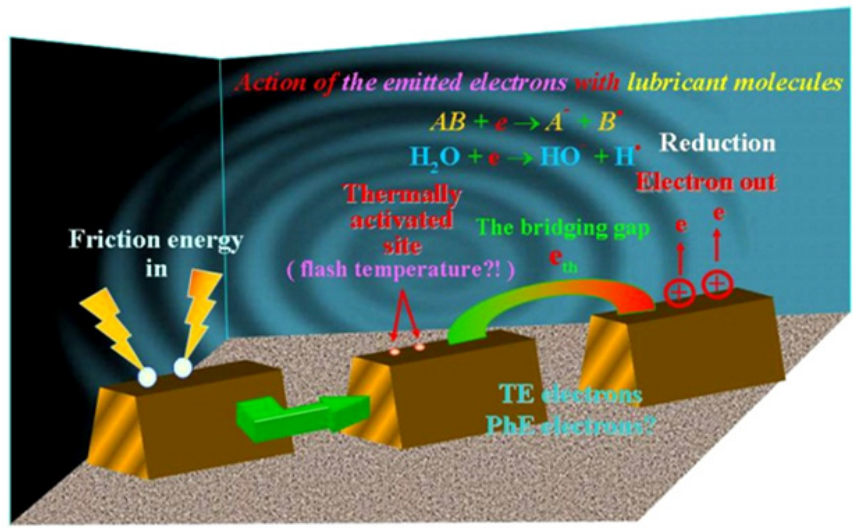

Figure 3. Initiation process of tribochemical reactions by the mechanical action.

\section{Triboemission and triboplasma}

\subsection{Triboemission}

Triboemission is defined as emission of electrons, charged particles, lattice components, photons, etc., under dry mechanical action, eg. surface damage caused by fracture processes or conditions of boundary friction. The fresh generated surface sites form a real bridge between physics and chemistry of the wear processes. Figure 4 depicts a simple idea of the exo-electron emission (EEE) process.

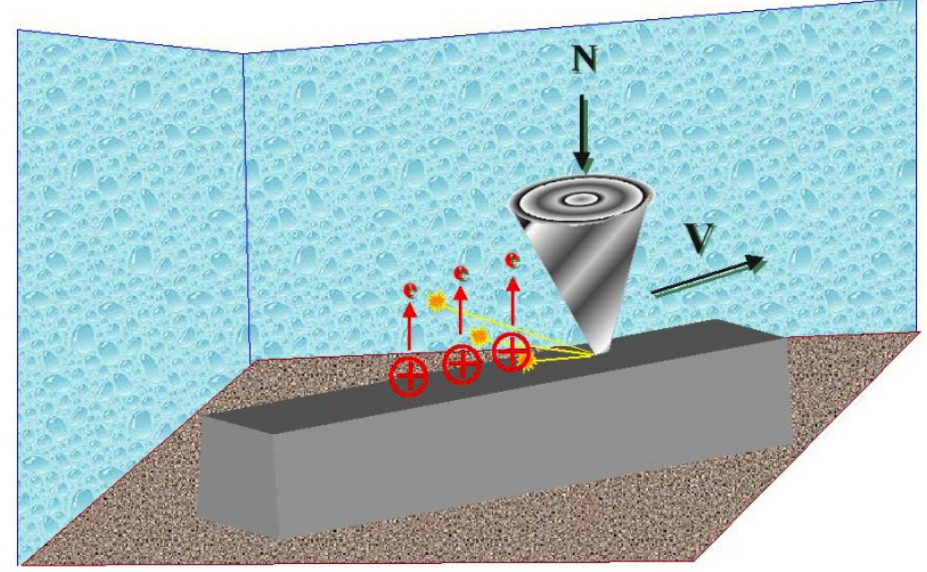

Figure 4. Exo-electron emission phenomenon.

There are many physical phenomena related to the wearing processes and mechanisms. These mechanisms are often connected with tribochemical reactions that are initiated by the surface enlargement effects. Figure 5 illustrates broadly the triboemission process. 


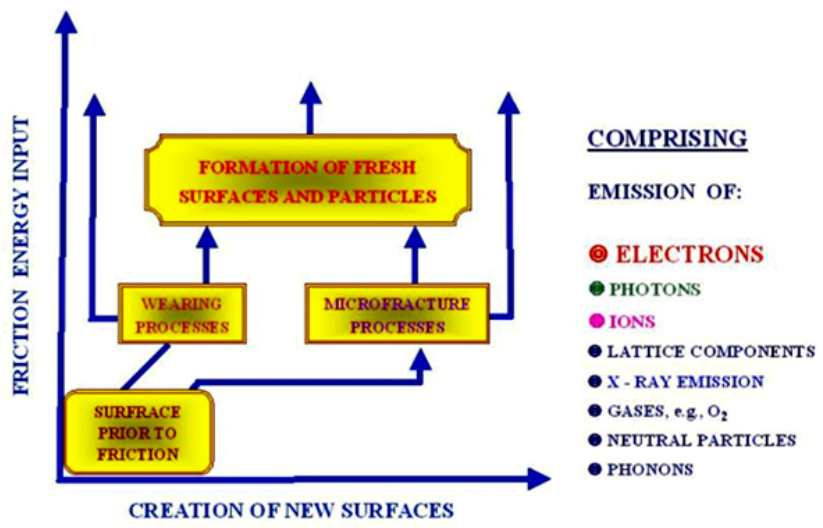

Figure 5. Physical processes evolved by friction.

Details are in reference [34], which distinguishes the following main types of triboemission phenomena: (a) emission of gas atoms and molecules, including emission of radicals and molecular clusters, (b) emission of electromagnetic radiation, (c) emission of electrons, (d) emission of ions, (e) emission of magnetic field, (f) emission of electric field including emission of electric charges and generation of tribocurrents, $(g)$ emission of noise, vibration and acoustic emission, (h) heat evolvement.

Emission of gas atoms and molecules at friction results from the competition gas release and gas adsorption processes. When at certain sliding conditions, the rate of gas adsorption exceeds the rate of gas release, total emission rate becomes negative. Such emission of negative rate has been called anti-emission. The triboemission phenomena are classified into two classes by physical nature: emission of particles ('corpuscular'), and emission of energy, as shown in Figure 6 [29,34].

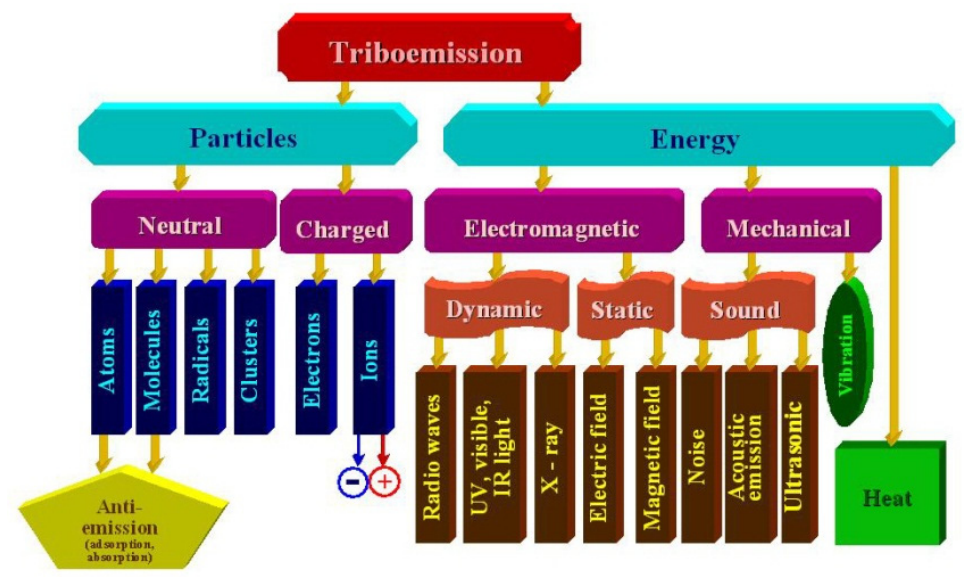

Figure 6. Classification of triboemission phenomena by physical nature. 
The particle emission includes neutral particles (atoms, molecules, radicals and clusters) and charged particles (electrons, negative ions and positive ions). Three main types of energy emission encompass: electromagnetic energy, mechanical energy and heat. Mechanical energy includes mechanical oscillations of various frequency ranges, i.e. vibration, noise, ultrasonic emission, acoustic emission, etc. Electromagnetic emission can be classified into static and dynamic. Static emission includes static electric and magnetic fields, while dynamic emission includes electromagnetic waves of various wavelengths, i.e. radio waves; IR, visible, UV light; and X-rays [34]. Significant research in the field of triboemission was carried out by Nakayama et al. [35]. Kim et al. [36] investigated electron and photon evolvement ( $\mathrm{phE}$ ) from magnesia $(\mathrm{MgO})$ under friction with diamond; they found that during indentation, prior to any fracture of $\mathrm{MgO}$, only phE was observed. The relative intensities of these signals can therefore be used to follow the progress and extent of plastic deformation and fracture during wear on millisecond time scales [36].

The work of Molina et al. [37-38] characterized triboemission of electrons from diamondon-alumina, diamond-on-sapphire, alumina-on-alumina, and diamondon-aluminum. The three ceramic-materials consistently showed burst-type negatively charged triboemission during contact at constant load and speed, while the aluminum system produced no significant emission. Decaying emission after contact ceased also was detected from the three ceramic systems for durations exceeding the minute-range [39]. For the cases of diamond-on-alumina and diamond-on-sapphire, energy spectrometry showed that a large fraction of the triboemitted negative charges were of low-energy (eg. 1-5 eV). This finding was of significant importance because in the NIRAM approach, it was hypothesized that the energy level of triboelectrons to initiate tribochemical reaction should be $1-4 \mathrm{eV}$ [40].

Interestingly, an early work [41] demonstrated that electrons of very low energy (EEE) can be produced from solids by mechanical deformation, X-ray irradiation and chemical reaction; if the excitation is not great enough to produce normal electron emission, steady EEE can be produced by steady excitation. Another early work [42] investigated EEE from aluminum abraded in different atmospheres and found that under high and ultra-high vacuum conditions, such electron emissions is associated with a shift of photo-electric threshold dependent upon the residual gas pressure to which the surface was exposed. It was evidenced that the initial growth stage of emission is due to the adsorption of water vapor, the subsequent decay being associated with oxidation [42]. EEE process is also combined with triboplasma. Extensive review paper [43] shows exo-emission as a sensitive method for the monitoring of the initial stages in the fragmentation of polymeric materials subjected to mechanical action, and demonstrates that the electrons emitted when solids (dielectric materials, metals, and polymers) are subjected to mechanical influences are capable of inducing the dissociative ionization of the water molecules adsorbed on the surfaces. The studies reviewed in [43] demonstrate unambiguously the interrelation between the mechanoemission phenomena and the mechanochemical processes. A correlation between the electron emission phenomenon and mechano-chemical processes in solids is also presented by Khrustalev [44]. 


\subsection{Triboplasma}

Elastic deformation is the first stage of the mechanical energy interaction between solids and leads to a change of the bond distances in the affected solid. Actually, it concerns mechanical energy transmission to solids. By and large, there are few processes for the transmission of mechanical energy by impact treatment. Heinicke in the Tribochemistry book [8] states the following: 'Immediately at the commencement of a grain colliding at high velocity with a solid surface it comes to a quasi-adiabatic energy accumulation and to the formation of an "energy bubble" at the point of action in the sub-microscopic deformation zone'. All these specific aspects are summarized in the phenomenological Magma-Plasma Model (MPM) [7,8]. As the MPM process is combined with the EEE process, it is of very significant importance for both mechanochemistry and tribochemistry. Figure 7 depicts the Magma-Plasma Model.

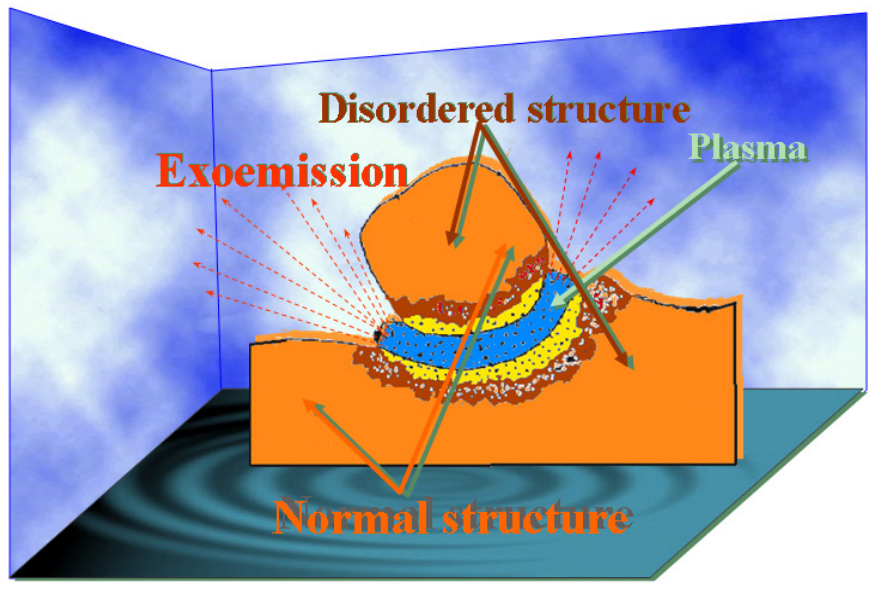

Figure 7. The Magma-Plasma Model (MPM) for the impact stress of flying grain.

The short life of the triboplasma causes no Maxwell-Boltzmann distribution, thus an equilibrium temperature cannot be given and the chemical process taking place in the excitation phase cannot be described by the laws of thermodynamics [8]. The highest stage of energy excitation changes dynamically into the next stage characterized by the relaxation of the plasma states and is termed as "edge-plasma" and "post-plasma". Work [45] describes the energy dissipation on solids activated by impact along with adequate discussion.

Mechanical forces make the atoms leave their equilibrium positions due to lattice vibration, alter bond lengths and angles of their atomic arrangements leading to electronically excited states (see Figures 3,5,7). The energy field incurred by the tribophysical effects, for example the EEE process, triboluminescence, triboplasma, crystal defects etc., initiates specific tribochemical reactions.

Mechanochemistry in terms of processes being triggered in the solid state chemistry, due to the application of mechanical energy, is extremely complex. Tribochemistry as its branch is 
even more entangled. Our present knowledge shows that mechanochemistry is also well combined with nanoscience [46].

\section{NIRAM and HSAB (hard and soft acids and bases) and catalytic approaches}

\subsection{Basic information on NIRAM}

In brief the NIRAM approach comprises the following major steps.

- Low-energy electron emission and generation of positively charged spots;

- Interaction of the emitted electrons with the lubricant molecules producing negative ions and radicals on tops of the rubbing surfaces;

- Reaction of negative ions with positively charged sites of friction surfaces;

- Other reactions, producing organometallic or inorganic film, which protects the rubbing surfaces from wear; if the shear strength is high chemical bonds of organometallic compounds are cleaved resulting in producing inorganic films and further radicals;

- Eventual destruction of protective layer caused by wear, followed by electron emission and subsequent formation of a new protective film.

Figure 8 illustrates the NIRAM reaction cycle. Most recent review [11] is on the NIRAM approach and shows its interrelationship with tribocatalysis. The application of the NIRAM approach explains the role of exoelectrons in some relevant tribochemical reactions detailed in [29].

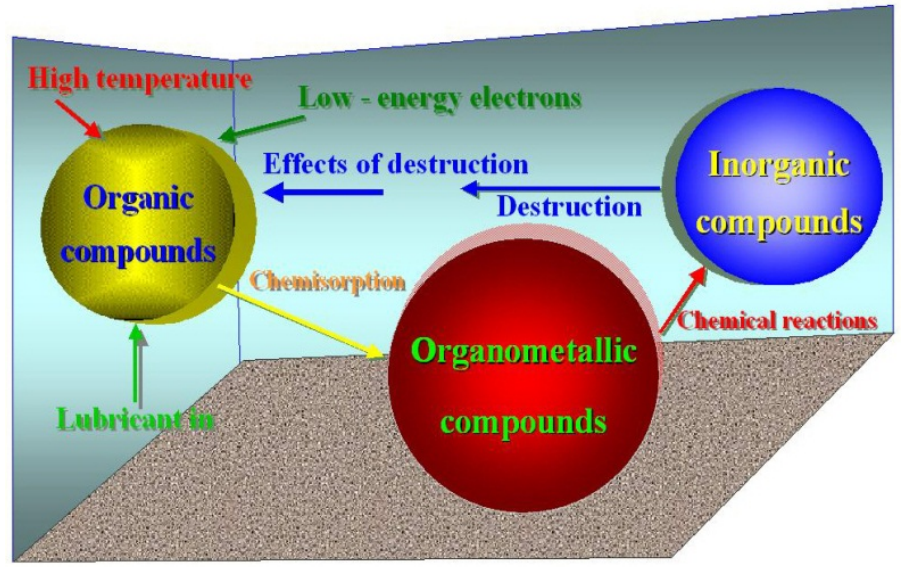

Figure 8. Reaction cycle of lubricant components on solid contacts during friction.

In summary, this boundary lubrication model proposes the formation of protective organometallic and inorganic layers on rubbing surfaces. The initiation reaction process is due to mechanical action evolving emission of low-energy electrons (1-4 eV) combined with flash temperature expressed in the thermionic emission (see Figure 1). 


\subsection{Examples of NIRAM applications}

\subsubsection{Traditional approach to mechanisms of AW and EP lubricant additives}

Tribochemistry of lubricating oils is overviewed in Pawlak's book [47]. Important and interesting approach to oil formulations and complex lubrication processes is assigned to inverse micelle. Figure 9 illustrates the inverse micelles involvement to interactions of base oils with major engine oil additives. The nature of the tribochemical film is the key to better understand the mechano-chemical processes that give rise to chemical films separating mating solid elements and thereby reducing wear and seizure.

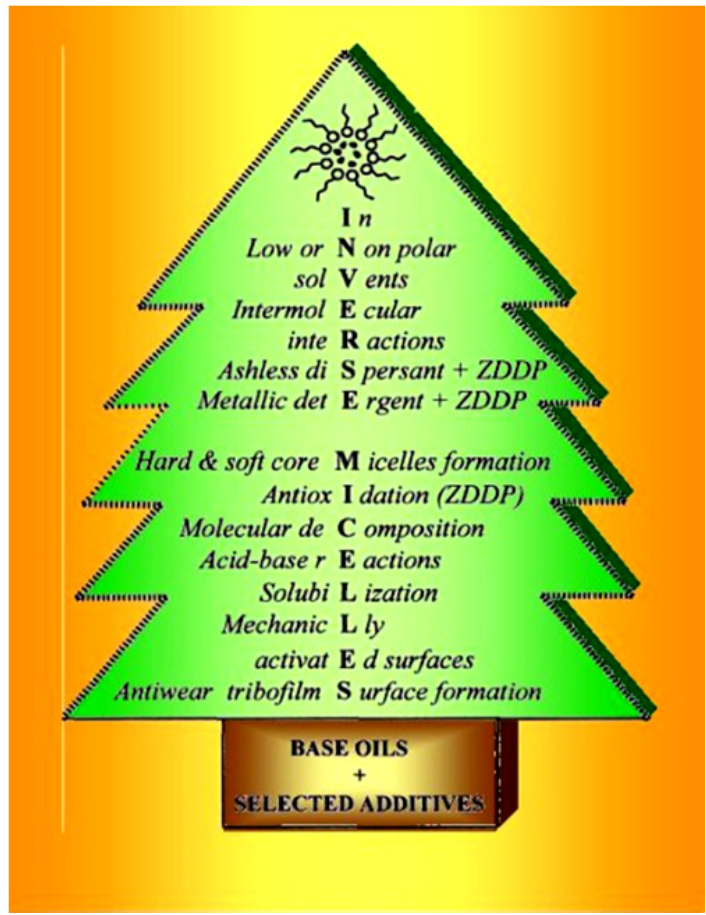

Figure 9. Tribochemical ‘TREE' according to reference [47].

The chemistry and tribology of EP additives have been recently well reviewed from the viewpoint of the presently accepted action mechanism [48]. On the other hand, chapters in the same book consider also the NIRAM approach [49-50]. Chapter on 'Tribochemistry' [51] details the NIRAM approach, presents specific reactive intermediates and mechanisms of selected organic compounds.

\subsubsection{Examples of NIRAM controlled tribochemical reactions}

Work [52] investigated tribochemical reactions of carboxylic acids under boundary lubrication conditions and it was found that, apart from regular salt (monodentate 
carboxylate group), salts with double bond in $\alpha, \beta$ position and chelating symmetric bidentate carboxylate group are formed. Figure 10 presents the proposed structure of iron salt with double bonding. These types of compounds are not produced under static conditions. It was found that bidentate surface configuration increased after the occurrence of the tribochemical reactions induced by surface rubbing. This proves this finding which was accounted for by the NIRAM approach. The new finding also clearly demonstrates the difference between tribochemical and thermochemical reactions. This finding is evidenced by other research results [53] on tribochemical and thermochemical reactions of stearic acid adsorbed on a copper surface.

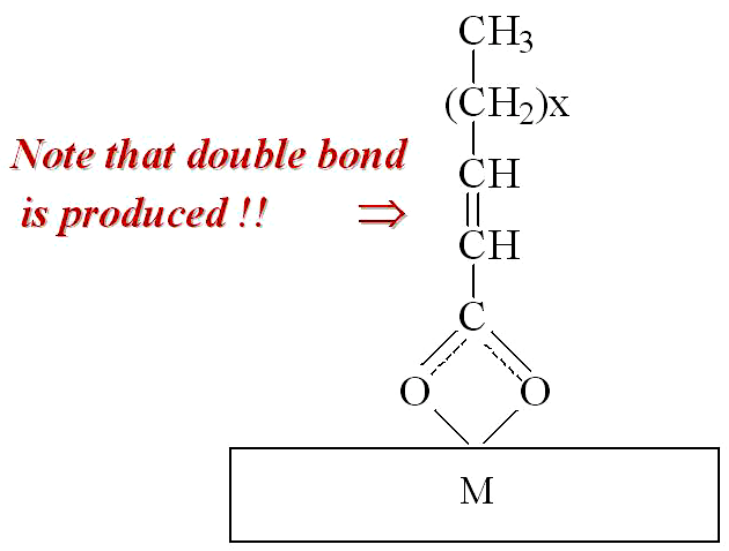

Figure 10. Chelating bidentate structure formed from caprylic acid [52].

Work [54], investigated changes of hexadecane under boundary lubrication conditions considering both (i) the chemical transformation of the bulk lubricant and (ii) the chemistry of products generated in wear tracks. Detailed analysis of hexadecane after friction tests showed that during the friction process aldehydes, alcohols and carboxylic acids are produced. This finding clearly indicates that tribochemical reactions cause significant changes of the apparently non-reactive paraffin hydrocarbon. The reaction process initiated by the frictional energy is in line with the NIRAM concept.

Regular monoester ester hydrolysis process produces alcohol and carboxylic acid. Work [55] aimed at checking role of hydrolytic reaction for the soap formation mechanism from esters. It was tried to find if typical conditions under boundary lubrication cause the hydrolysis of esters dissolved in hexadecane. Figure 11 reflects a ball wear reduction versus the additive concentration in hexadecane. These results enabled to state that the hypothesis saying 'during the friction process under boundary lubrication conditions lubricated by aliphatic esters, the ester hydrolysis process cannot proceed without an adequate catalyst' is well substantiated. Thus, it is possible to conclude that the soap formation mechanism from esters under boundary lubrication conditions is controlled by the NIRAM approach [56]. 


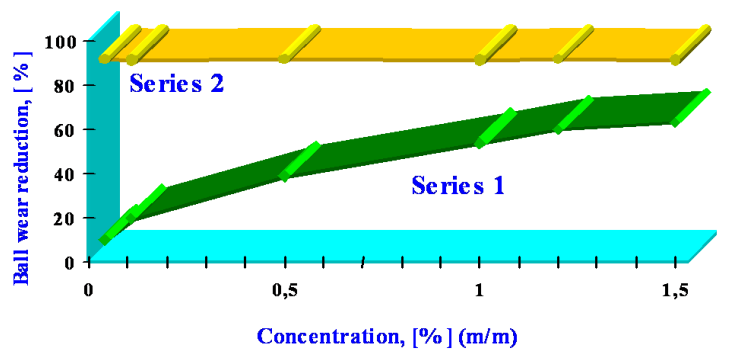

Figure 11. Influence of the solution concentration of octadecyl palmitate (Series 1) and equimolar mixture of palmitic acid and octadecanol (Series 2) in hexadecane on the ball wear [55].

The ester reactive intermediates produced via the dissociative electron attachment, showing two types of $\mathrm{C}-\mathrm{O}$ bond cleavage, are presented in Figure 12. The first bond cleavage type produces carboxylate anion ( $\mathrm{RCOO}^{-}$) and the free radical $\mathrm{R}^{\cdot}$. The second bond cleavage generates the alkoxide anion $\left(\mathrm{RO}^{-}\right)$and the $[\mathrm{R}-\mathrm{C}=\mathrm{O}]^{\cdot}$ free radical that undergoes further reactions. To produce free radicals and thereby initiate the free radical chain reaction process either heat or catalyst is needed. Therefore, an electron attachment in this case acts as a catalyst. The exoelectron dissociative attachment to an ester molecule yielding two types of negative ions is clearly evidenced by the electron attachment mass spectrographic results [57].

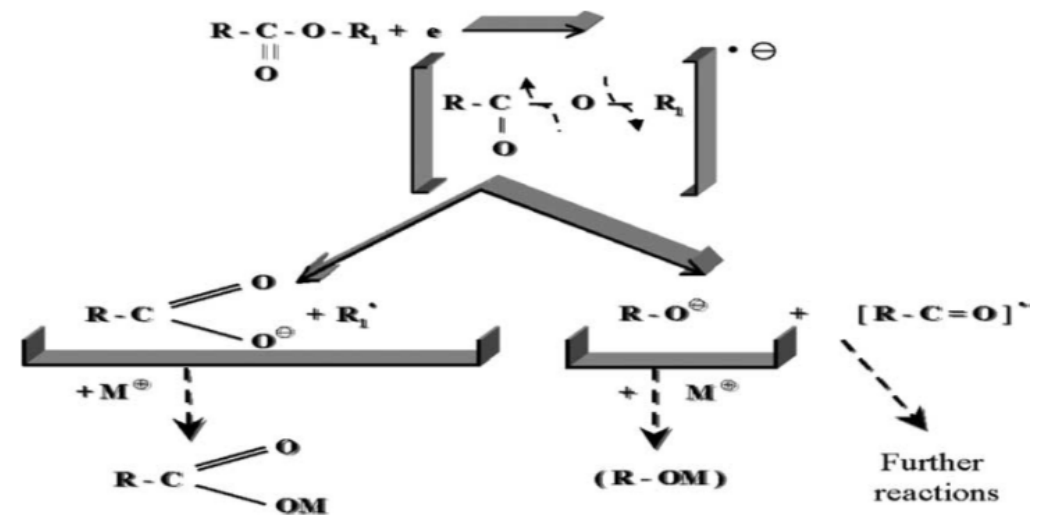

Figure 12. Ester reactive intermediates generated by electron attachment.

\subsection{Basic information on NIRAM-HSAB theory}

Gilman [58] emphasizes that mechanochemical effects have often been attributed to strain energy assisting thermal energy. When covalent bonds are bent or sheared, the energies of their highest occupied molecular orbitals (HOMO) are raised, whereas the energies of their lowest unoccupied molecular orbitals (LOMO) are lowered and, the gap between levels determining a bond's stability is decreased [59]. If the strain becomes big enough to close the gap, the bonding electrons can move freely, and, the reaction can take place immediately. The simplest way of illustrating that phenomenon is based on a generalized NIRAM-HSAB 
theory and provides its possible application for accounting for some tribochemical processes under boundary lubrication conditions. Figure 13 [11] depicts the model.

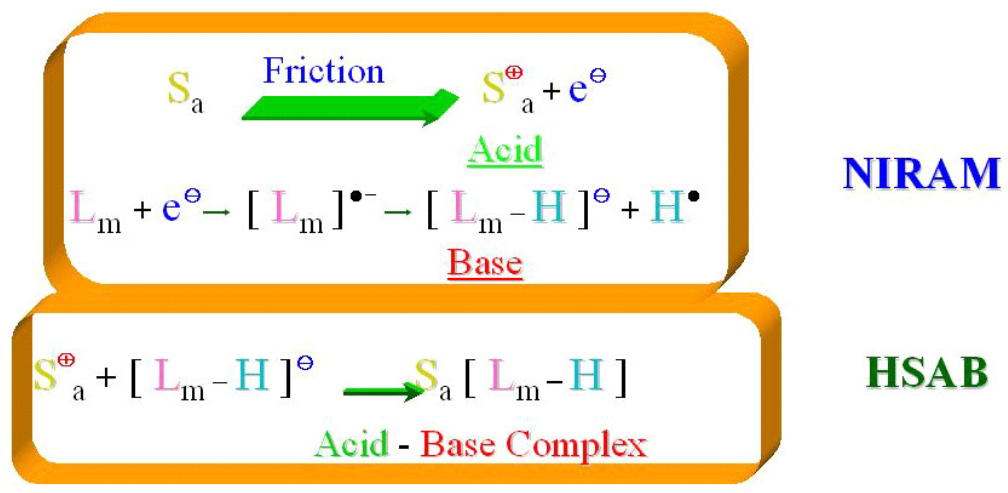

Figure 13. NIRAM-HSAB lubrication mechanism approach: $\mathrm{S}_{\mathrm{a}}$, tribological microsurface area; $\mathbf{L m}$, lubricant molecule; and $\mathrm{e} \Theta$ is a low-energy electron emitted under boundary lubrication conditions

Presently this model has been applied to account for very complex tribochemistry of silicon nitride $\left(\mathrm{Si}_{3} \mathrm{~N}_{4}\right)$ [60]. The tribochemical reaction pathway of $\mathrm{Si}_{3} \mathrm{~N}_{4}$ was accounted for in terms of the NIRAM-HSAB theory, in which tribo-electrons play an important role to decrease the activation energy. This may explain the reason why some products can be formed only by friction such as the tetrasiliconalkoxide obtained in lubrication with alcohols. Tribochemical wear provides flat surfaces, and decreases stresses since insoluble tribo-products act as lubricants by forming protective films, such as hydrated silicon oxides when water is present, and silicon alkoxide polymers in the case of alcohols. Figure 14 accounts for tribochemistry of $\mathrm{Si}_{3} \mathrm{~N}_{4}$ with water.

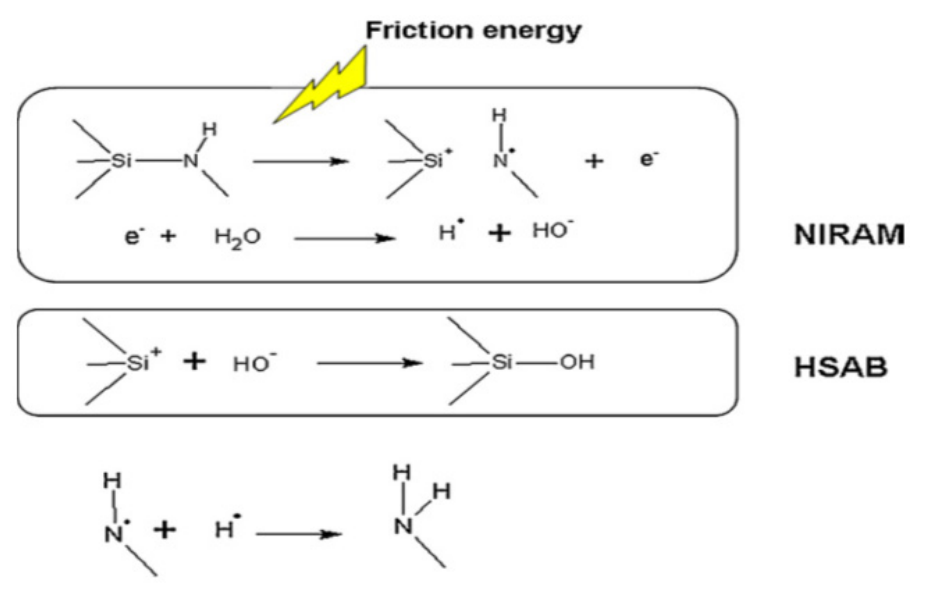

Figure 14. Interpretation of the tribochemical reaction of water with silicon nitride based on NIRAMHSAB theory [60]. 
Applying the NIRAM-HSAB approach, the formation of silicon compounds from $\mathrm{Si}_{3} \mathrm{~N}_{4}$ lubricated by alcohols is represented in Figure 15, which follows the scheme of Figure 14. The enhanced reactivity of silicon nitride under friction relates to active sites such as dangling bonds, and the action of tribo- and/or thermionic emissions. It should be noted that, according to Figure 16, the intermediate is the anion $\mathrm{RO}^{-}$, which is formed also during polymerization of the silicon alkoxide [61-62], thus further increasing the rate of the tribochemical reaction.
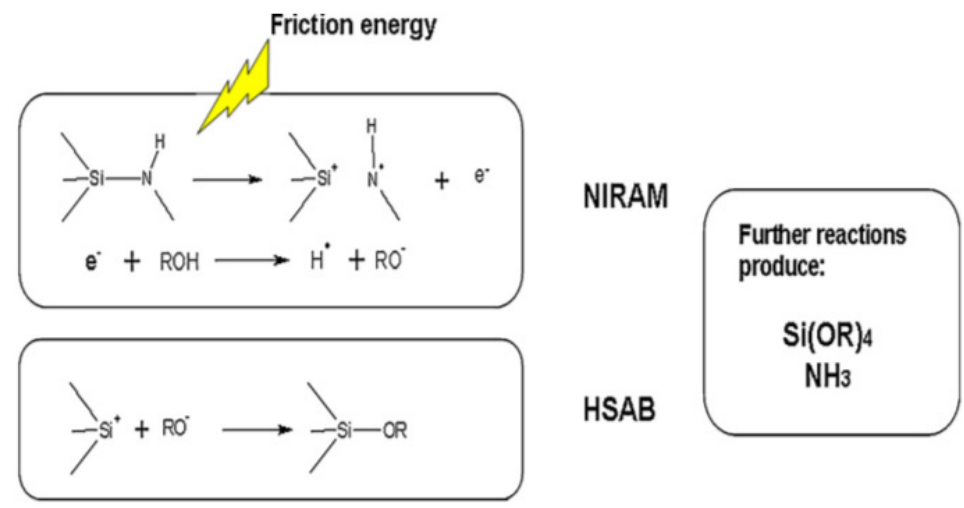

Figure 15. Interpretation of the tribochemical reaction of alcohols with Si3N4 based on NIRAM-HSAB theory [60].

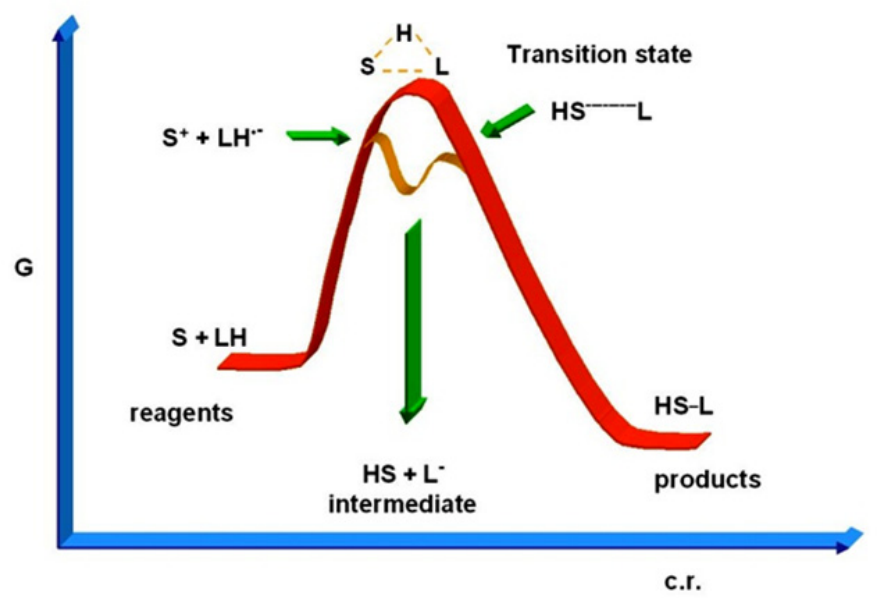

Figure 16. Free energy Gibbs (G) curve as function of the coordinate of reaction (c.r.). $S$ is an active surface site, $\mathrm{LH}$ - lubricant molecule ( $\mathrm{H}$ is hydrogen, $\mathrm{L}$ is the hydrocarbon branch of the lubricant) [60].

In the intermediate depicted in Figure 16, electron and proton are exchanged between the two reagents $S$ and $L$. This exchange mechanism is based on the subatomic particles involved in chemistry and, it is clear relationship between the intermediate and transition 
state reflected in the product formed. So that the tribochemical reaction pathway of silicon nitride has been accounted for in terms of the NIRAM-HSAB theory, in which triboelectrons play an important part to decrease the activation energy or increase the reaction rate. This may explain the reason why some products can be formed only by friction such as the tetra silicon alkoxide obtained in lubrication with alcohols.

\subsection{Catalysis and tribocatalysis}

Catalysis is the phenomenon of a catalyst action and the catalyst is a substance that increases the rate at which a chemical system approaches equilibrium, without being consumed in the process [12]. To initiate thermochemical reactions, the reaction system temperature should be increased to overcome the activation energy barrier (see Figure 16). The same is due to the catalytic process, but the catalyst lowers the reaction activation energy. Usually, it is demonstrated by the difference of the activation energy $\left(\mathrm{Ea}_{\mathrm{a}}\right.$. Considering tribocatalytic reaction as the tribochemical one enhanced by the rubbing of catalyst, most recently it was demonstrated that in the tribocatalytic ethylene oxidation, the activation energy (Ea) with friction was less than $2 \%$ of the thermochemical reaction [63].

Activation energy lowering is a fundamental principle of catalysis and it applies to all forms of catalysis. For catalytic process to occur, a chemical interaction between catalyst and the reactant-product system is necessary, however this interaction should not change the chemical nature of the catalyst. With a catalyst, the energy required to go into the transition state decreases, thereby decreasing the energy required to trigger the reaction process. The rates of chemical reactions increase as temperature increases. Chemical reactions have rate constants approximated by the Arrhenius equation

$$
k=A \exp ^{(-E a / R T)}
$$

where $\mathbf{A}$ is the pre-exponential factor for the reaction. Heterogeneous catalysts provide a surface for the chemical reaction. Most heterogeneous catalysts are solids that act on substrates in a liquid or gaseous reaction mixture.

Reference [64] reviews and discusses the effect of mechanochemical activation on the catalytic properties of different systems. It is noted that the activity of a catalyst with defects is somewhat higher than its activity in the equilibrium state, emphasizing that the degree of increase in activity depends on the amount of the excess energy stored. It is stressed that the energy stored in defects influences the catalytic properties through the variation of thermodynamic potentials.

Practically all types of chemical reactions are accompanied by a change in energy. Some of them release energy to their surroundings mostly in the form of heat and thus are called exothermic. Conversely, some reactions need to consume heat from their surroundings to proceed. These reactions are called endothermic. Reactions that proceed immediately when two substances are mixed together are called spontaneous reactions. The application of mechanical energy associated with friction releases physical processes that can be the cause 
of tribochemical reactions of solids with lubricant molecules. Figure 17 demonstrates a general approach to physical and chemical events relating to boundary lubrication conditions.

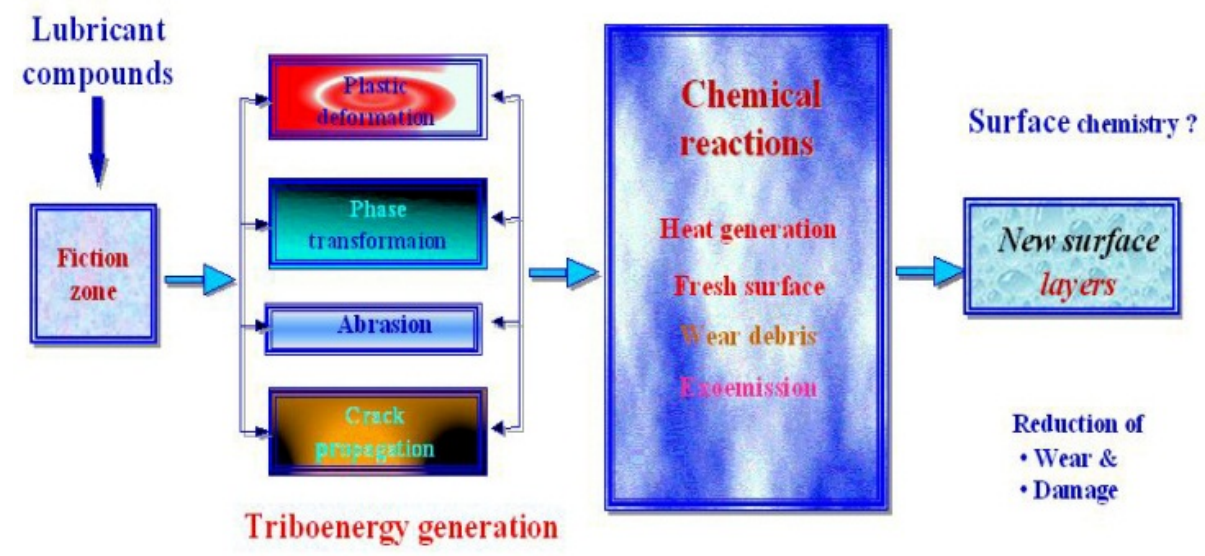

Figure 17. Major physical and chemical events in the boundary lubrication contact.

The common denominator of these reactions is that they are triggered by low-energy electrons. This statement is relevant to hypothesis of the present author saying that the intermediate reactive species of both mechanochemical and tribochemical reactions are produced by the same mechanism. Mechanolysis is very special branch of mechanochemistry, particularly from the view-point of water splitting technology.

\section{History and present state of the mechanochemistry and its relation to tribochemistry}

\subsection{Summary of historical background based on Takacs's work}

The feasibility that chemical reactions in solids can be initiated by mechanical deformation and/or tribological contact, had been considered for almost 120 years back. At that time M. Carey Lea [1] wrote 'Mechanical force can bring about reactions which require expenditure of energy, which energy is supplied by mechanical force precisely in the same way that light, heat, and electricity supply energy in the endothermic changes which they bring about'.

Typical historical reviews of mechanochemistry by Takacs [2-3] have presented Matthew Carey Lea as the first systematic researcher on the chemical effects of mechanical action. Mechanical energy triggering chemical reactions had been of particular significance in development of mechanochemistry, known for over two centuries.

Early twentieth century (1919) Ostwald considered mechanical energy influence on chemical reactions and coined the term 'mechanochemistry'. However, at that time Ostwald was not able to say anything on the independent character and the importance of this field of 
chemistry. Another detailed review paper [6] on mechanochemistry deals also with its historical development. Superb experimental historical achievement of Carey Lea relates to the cinnabar (HgS) decomposition by trituration in a copper mortar with a copper pestle to produce $\mathrm{Hg}$ element and thereby to combine mechanochemistry with tribochemistry, due to the fact that trituration relates to friction 'tribos'. This clear description of the mechanochemical action on initiation of chemical processes is described in Takac's papers [3] as follows 'Native cinnabar (mercuric sulfide, HgS) was rubbed with vinegar in a copper mortar with a copper pestle yielding the liquid metal.' According to Tackacs [3] the source of such information is assigned to "Theophrastus' History of Stones" [65], a 1774 English translation of Theophrastus' Greek original written at the end of the $4^{\text {th }}$ century B.C. It is the earliest preserved text on any subject related to chemistry or metallurgy. Thereafter, the sentence on the preparation of mercury is very probably the earliest reference to any mechanochemical reaction, extending the documented history of the process by two and half millennia [3].

\subsection{Action mechanism of the first mechanochemical discovery}

Another paper [66] reviews widely and precisely mechanochemistry of solids. Describing reaction of mechanochemical synthesis a kind of conclusion is clearly expressed "One of the key problems to be solved in this area is what is the start, or trigger, of the self-propagating hightemperature synthesis process? Is the Joule heat or the formation of contacts between the particles, which would be sufficient for self-heating in the contact zone to transfer the process into the regime of self-propagating high-temperature synthesis".

This Section demonstrates how the NIRAM approach might be applied to account for the mechanism of cinnabar ( $\mathrm{HgS})$ decomposition to produce $\mathrm{Hg}$ element and thereby to interconnect mechanochemistry with tribochemistry. It is hypothesised that both typical mechanochemical and tribochemical reaction processes are mostly triggered by triboemitted negative particles. The proposed decomposition mechanism encompasses three major steps. Mechanical action emits low-energy electrons. The emitted electrons interact with $\mathrm{Hg}=\mathrm{S}$ to produce negative-ion-radical (NIR) reactive species. NIR reacting with $\mathrm{O}_{2}$ produces unstable $\mathrm{HgSO}_{2}$ which decomposes to metallic $\mathrm{Hg}$ and $\mathrm{SO}_{2}$. In brief summary, the NIRAM approach can demonstrate the first feasible mechanism of the cinnabar mechanochemical decomposition to produce $\mathrm{Hg}$ element and thereby to interconnect mechanochemistry with tribochemistry.

Now we need to consider the mechanism of cinnabar $(\mathrm{HgS})$ decomposition by trituration in a copper mortar with a copper pestle to produce $\mathrm{Hg}$ element and thereby to more interconnect mechanochemistry with tribochemistry, due to the fact that trituration relates to friction 'tribos'. In this case also the reaction of $\mathrm{HgS}$ with copper $(\mathrm{Cu})$ is taken into account. The whole reaction is:

$$
\mathrm{HgS}+\mathrm{Cu} \rightarrow \mathrm{Hg}+\mathrm{CuS}
$$

The reaction might proceed via the negative-ion-radical reactive intermediate 


$$
\cdot \mathbf{H g}-\mathbf{S}^{\ominus}
$$

The intermediate interacting with copper positively charged sites can produce $\mathrm{CuS}$ and $\mathrm{Hg}$. It is assumed that during the trituration in a copper mortar with a copper pestle, electron $(\mathrm{e} \Theta)$ is emitted and positively charged copper atom $\left(\mathbf{C} \mathbf{u}^{\oplus}\right)$ is produced. Thus, the NIRAM based reactions take place:

$$
\begin{gathered}
{ }^{\bullet} \mathrm{Hg}-\mathrm{S}^{\ominus}+\mathrm{Cu}^{\oplus} \longrightarrow{ }^{\bullet} \mathrm{Hg}-\mathrm{S}-\mathrm{Cu} \\
{ }^{\cdot} \mathrm{Hg}-\mathrm{S}-\mathrm{Cu}+{ }^{\cdot} \mathrm{Hg}-\mathrm{S}-\mathrm{Cu} \longrightarrow 2 \mathrm{Hg}+2 \mathrm{CuS}
\end{gathered}
$$

Please note that here we have to take into account not only $\mathrm{CuS}$ but also 2Cu2S:

$$
\mathbf{C u}-\mathbf{S}-\mathbf{S}-\mathbf{C u}
$$

other considered compounds might include Cu2S and CuS2.

\subsection{Comparison of the NIRAM approach with the generation process of mechano-anion-radicals (MARs) in polymers}

The NIRAM concept is based on the hypothesis that low energy electrons (1 to $4 \mathrm{eV}$ ), emitted from rubbing surfaces, can be the key factor in some tribochemical reactions $[11,29,40,51]$.The concept of the MARs generation process in polymers is based on the polymer mechanical degradation via two types $\mathrm{C}-\mathrm{C}$ bond cleavage: (i) homogeneous and (ii) heterogeneous. Generation process of polymer mechano-anions is combined with the polymer triboelectricity phenomenon caused by mechanical scission of the polymer main chain on a friction surface.

It is generally known that the friction between dielectrics results in the buildup of electric charge. The energy of electrons emitted from polymers amounts to scores of $\mathrm{keV}$, with the emission itself being a lengthy, slowly decaying process; such electrons are called mechanoelectrons. Most recent paper [67] reports (see also references in [67]) the mechano-emission arises as a result of the ionization of surface traps at the expense of the energy which is released in the annihilation of the defects which are formed during cleavage; the slow electrons are accelerated in the field of negatively charged segment of the freshly cleaved surface. Slow electrons appear upon the ionization of surface traps. The energy of the electrons was evaluated from the deviation of the electron beam in a magnetic field and by measuring their passage through obstacles.

At this point the following question is asked. Is here the only mechanism involved that electron transfers from the mechano-anion $\left(R^{\Theta}\right)$ produced via heterogeneous bond cleavage as suggested by Sakaguchi et al. [68]? The electron transfer from $\mathrm{R}^{\Theta}$ was documented by the following reaction in dark with tetracyanoethylene (TCNE) electron scavenger as follows:

$$
\mathbf{R}^{-}+\text {TCNE (mixing in the dark) } \longrightarrow \mathbf{R}^{\bullet}+\text { TCNE }^{-\bullet}
$$


Figure 18 summarizes all the process steps, where $\bullet \mathrm{R} 1$ and $\bullet \mathrm{R} 2$ relate to free radicals of homogeneous $\mathrm{C}-\mathrm{C}$ bond cleavage. $\mathrm{R}^{-}$and $\mathrm{R}^{+}$relate to anion and positive ion species of the heterogeneous polymer bond scission. Radical $\mathrm{R} \cdot$ concerns electron transfer from the negative ion $\mathrm{R}^{-}$(anion) to TCNE either during mixing or photo irradiation.

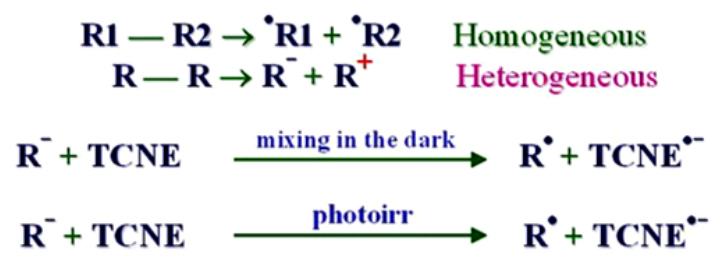

Figure 18. Illustration and suggested evidence for heterogeneous $C-C$ bond cleavage based on work [68].

The electron transfer reaction in the dark at $77 \mathrm{~K}$ is promoted by physical mixing of fractured sample in the vibration glass ball mill and, after milling; the fractured sample was dropped into the ESR sample tube under vacuum in the dark at $77 \mathrm{~K}$ and photo irradiated using an IR lamp with a glass filter corresponding to visible light [68]. Thus, everything is clear for the irradiation effect due to electron detachment. On the other hand, for reaction (7) here an alternative mechanism is proposed, as detailed in Fig. 19.

$$
\begin{gathered}
\text { Polymer }+ \text { TCNE (mixing in the dark) } \rightarrow \\
\mathbf{R}^{+} \text {(positively charged site) }+\mathbf{R}^{\bullet} \text { (free redical) }+\mathbf{e} \text { (emited electron) } \\
\text { TCNE }+\mathbf{e} \rightarrow \underline{\mathbf{T C N E}^{\circ}-} \\
\text { and thus, according to the NIRAM approach, } \\
\text { the electron attachment to } \\
\text { TCNE } \\
\text { replaces the heterogeneous } \mathrm{C}-\mathrm{C}^{-} \text {bond cleavage } \\
\mathbf{R}-\mathbf{R} \rightarrow \mathbf{R}^{-}+\mathbf{R}^{+}
\end{gathered}
$$

Figure 19. Application of the NIRAM approach to account for the mechano-anion-radical generation

Actually, generation of mechano-anion-radicals relates strictly to triboelectricity and is reviewed in reference [68]. It cites a wide range of papers which aimed at finding evidence for both heterogeneous $\mathrm{C}-\mathrm{C}$ bond scission and polymer triboelectricity. The review strongly suggests production, eg. mechano-anions induced by mechanical fracture of PCV. EPR studies provide evidence TCNE radical-anion generation. However, the formulation of a satisfactory theory to account for the triboelectricity of polymers has yet to be established. The same is due to clear evidence for heterogeneous $C-C$ bond scission. An extension of the NIRAM approach to better understand the mechano-anion-radicals allows considering tribochemistry as a branch of mechanochemistry.

Triboelectricity or contact electrification of materials is a very complex phenomenon. According to [69] the first studies on contact electrification were carried out over 2500 years ago, when 
experiments showed that rubbing amber and wool caused the two materials to become oppositely charged. Our scientific understanding of contact electrification has not progressed too much and, it is still not known what species is being transferred between the wool and amber to generate the charge, and how rubbing influences the process [70]. That review paper concludes with a discussion that virtually all questions involving electrostatics are in fact open ones and the size of existing particles is of special importance. It was assumed and partly evidenced that small particles charge negatively and the larger particles should charge positively. Fig. 20 illustrates the effect of contact geometry for contact charging of bulk-scale surfaces of identical insulator materials [70] and, some works referred in it.

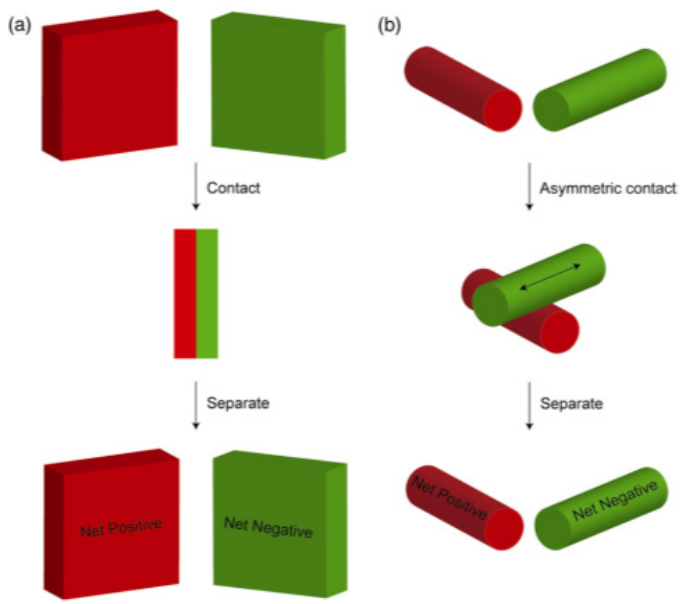

Figure 20. Contact between two material surfaces in a symmetric fashion resulting in a net positive charge on one surface and a net negative in an apparently random direction (a); contact between two materials' surfaces in an asymmetric fashion usually results in a net negative charge on the surface with the smaller contacting area and net positive charge on the surface with the larger contacting area $(b)$. Figure taken from Reference [70].

\section{Present knowledge on mechanochemistry and tribochemistry}

\subsection{Brief introduction}

Particularly important research and practical application of mechanochemistry is well reflected in INCOME (International Conference on Mechanochemistry) series of special meetings initiated in 1993 by International Mechanochemistry Association (IMA). IMA is the associate member of International Union of Pure and Applied Chemists (IUPAC). These conferences regularly serve as a common platform to bring together all stakeholders from academia, research and development organisations, along with industry to foster the growth of the discipline [71]. The first INCOME meeting was held in Slovakia (1993). Participants from 25 countries of 4 continents took part at the meeting. This international forum was preceded by eleven All-Union Symposia on Mechanochemistry and Mechanoemission. 
INCOME 2011 focused on mechanochemistry and mechanical alloying, was held in Herceg Novi, Montenegro. The conference aimed at providing a forum for presentation of new results, identification of current research and development trends along with future directions and, promoted interactions dealing with various aspects of the discipline. Presented research papers concerned both mechanochemistry and tribochemistry. By and large, they demonstrated the progress of studies on the chemical and physicochemical processes proceeding in solids under mechanical action.

\subsection{Major recent review papers}

Some review papers have already been described in previous sections. They specifically relate to mechanochemistry $[46,66]$ and/or tribochemistry [6,11,29]. The most recent extensive critical review paper [72] aims at providing a broad but digestible overview of mechanochemical synthesis, that is reactions conducted by grinding solid reactants together with no or minimal solvent. This critical review includes over 300 references focused on the historical development, mechanistic aspects, limitations and opportunities of mechanochemical synthesis. It emphasizes that although mechanochemistry has historically been a sideline approach to synthesis, presently it may move into the mainstream because it is increasingly apparent that it can be practical, and even advantageous [72]. This is because it provides the opportunities for developing more sustainable technologies. Additionally, synthesis of metal organic frameworks (MOFs) has to be mentioned here, as it have become presently one of the most intensely researched areas of materials chemistry and, it might relate to both mechanochemistry and tribochemistry.

An earlier detailed review paper generally aimed at mechanical activating of covalent bonds [73], also considers mechanochemistry of crystals, metals, alloys, and polymers. The latter is related to already discussed in detail heterogeneous $\mathrm{C}-\mathrm{C}$ bonding splitting in polymers [68] (see Section 5.3). By the employing of mechanochemical solid-state reaction, Fujiwara and Komatsu synthesized a novel $\mathrm{C}_{60}$ dimer linked by a silicon bridge and a single bond [74]. The novel $\mathrm{C}_{60}$ dimer was synthesized using a high-speed vibration milling (HSVM) technique and, the product obtained was fully characterized by a wide variety of sophisticated analytical techniques. The electronic interaction between the two $\mathrm{C}_{60}$ cages was evidenced by the electrochemical method. For instance, in these dimers, the two fullerene cages are connected by sharing a cyclobutane ring. the mechanochemical solid-state reaction of $\mathrm{C}_{60}$ with alkyl or aryl halide in the presence of alkali metals was found to cause alkylation or arylation of $\mathrm{C}_{60}$ possibly by the intermediacy of the $\mathrm{C}_{60}$ radical anion [74]. The mechanochemical reaction of the fullerene with dichlorodiphenylsilane ( $\mathrm{Ph} 2 \mathrm{SiCl} 2)$ and lithium ( $\mathrm{Li})$ metal, under the solvent free conditions, allowed synthesizing the $\mathrm{C}_{60}$ dimer fused with a silacyclopentane ring, as shown below [74].

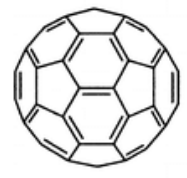

$\mathrm{Ph}_{2} \mathrm{SiCl}_{2}$, Li

High-Speed Vib ration Milling

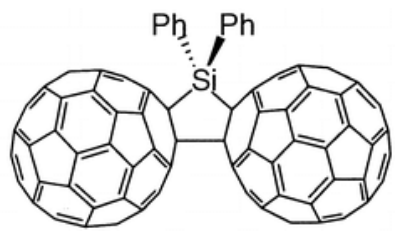




\subsection{Practical aspects of mechanochemistry}

Very detailed review publications [72-73] include a wide range of industrial applications of mechanochemistry and underline the need for sustainability brought about by the Kyoto Treaty and the increasing global demand for products leading to an increase in sustainable manufacturing processes. Such processes and/or new technologies can lower environmental demands. Improved sustainability can be realized in the form of reduced energy use, less organic solvents, better selectivity and reduced waste. Recent well specified study [75] presents several advantages of mechanochemical technology, such as simple process, ecological safety and the possibility of obtaining a product in the metastable state. Thus, it gives an overall review of the mechanochemistry applications in waste management. Interestingly to note that based on that study, the modification of fly ash and asbestos containing wastes (ACWs) can be achieved by mechanochemical technology (MCT). Finally, MCT provides with a prospective application in pollution remediation and also waste management. Hazardous metal oxides can be transformed into easily recyclable sulfide by mechanochemical sulfidization; the waste plastics and rubbers, which are usually very difficult to be recycled, can also be recycled by mechanochemical technology [75]. At this point the importance of waste-free mechanochemical synthesis and production should also be noted [5].

Another study [76] demonstrates that the mechanochemical treatment of an expired drug as ibufren, may be very useful and non-polluting way to change the bioactive molecule of a pharmaceutical formulation into non-toxic product. In the degradation mechanism two major steps are considered. The first one in the degradation process that leads to the detoxification of the drug, is induced by the presence of a co-reagent aluminum hydroxide. The second step relates to oxidative decarboxilation to an intermediate stable benzyl radical which, reacting in the presence of oxygen during milling, produces several products. The number of the generated products is controlled by the milling time. Thereafter, mechanochemical treatments are environmentally sound for general approach to detoxify chemical-pharmaceutical waste. Thus, in this case a type of molecular mechanolysis without solvent or usual thermal contribution can be considered [76].

Extension of mechanochemistry practical applications is broadly described by Todres in the book on both mechanochemistry and tribochemistry [77]. The specificity of the Todres' book is that it discusses chemical reactivity of organic molecules mechanically treated separately or together and, describes mechanochemically initiated polymerization, depolymerization and mechanolysis. It also considers lubricant design and lubricity process. Organic solids/materials are very liable to attrition representing wear caused by friction (tribos) and therefore relating to tribochemistry. This is evidenced by considering detailed organic reactions with lubricating layers.

\subsection{How mechanochemistry is entangled with tribochemistry}

\subsubsection{Selected books and review publications}

Mechanochemistry comprises a wide branch of the reactivity research of solids activated by mechanical action. It also deals with mechanisms of solid-phase reactions, aiming at making 
new materials by non-traditional methods. Nowadays, it is an established field of materials science and solid-state chemistry [58]. The importance of mechanochemistry is evidenced by several books clearly presenting its scientific and practical achievements [46,78-80].

The latter book [80] is on powder technology and deals with a variety of particles, from submicrometer to large grains and gravels and from liquid mist or droplets to bubbles, as well as solid particles and aggregates. As it considers with two-phase and three-phase mixtures, it relates to work in different science and engineering fields and, thereby demonstrate a bridge between pure mechanochemistry, inorganic chemistry and/or technology, organic chemistry and/or technology and, tribochemistry in its broad meaning. Thereby, it evidences simultaneously how mechanochemistry is complex and entangled with tribochemistry. On the other hand, a lot of natural and artificial phenomena encountered in our daily lives may be accounted for by knowledge of powder technology.

Some books are related to tribology $[15,28]$ or tribochemistry [7-8], however they also consider mechanochemistry. Another one tends to tribochemistry via organic mechanochemistry [76]. The same is due to review papers [13, 16-17] and book chapters [48-50].

In summary, presently both mechanochemistry and tribochemistry appear to be a science with a sound theoretical foundation. Their major benefits include lower reaction temperatures and increased reaction rate. As a consequence, processing of materials can be performed in simpler and less expensive reactors during shorter reaction times.

\subsubsection{Mechanochemistry vs. tribochemistry}

It is known that some chemical substances react differently when exposed to mechanical and thermal energy. The term mechanochemistry was coined by Oswald for the corresponding branch of chemical physics. In this sense, mechanochemistry should be considered along with thermochemistry, electrochemistry, photochemistry, sonochemistry, chemistry of high pressures, shock waves, or microwave effects [76]. In fact, organic solids are very liable to attrition; inorganic materials appear to be more resistant [81] and the attrition represents wear caused by rubbing or friction which already relates to tribochemistry.

At this point we need to come back to the Todres book [77], which outlines the main regularities governing transformations of mechanically activated organic compounds and discusses physical processes that affect these transformations. Some chapters concern more specifically the mechanically induced reactions of organic synthesis and the chemical transformations of organic participants of boundary lubrication. As already indicated, the mechanically induced synthesis of the desired organic compounds is advantageous in the sense of rates of formation.

Summarily, this is preferred over expenses required for mechanical activation (say, for the electricity spent to rotate a mill); chemical forces arise from summation of excess enthalpy of individual participants and that of chemical interaction. Thus, such chemical processes should be described in terms of the tribochemistry action mechanisms. 


\subsubsection{Similarities between mechanochemistry and tribochemistry}

Definitions of mechanochemistry and tribochemistry, formulated 50 years ago [7,8], are generally accepted and, the following definitions have been selected for this Chapter. Mechanochemistry is a branch of chemistry which is concerned with chemical and physicochemical transformations of substances in all states of aggregation produced by the effect of mechanical energy. Tribochemistry is a branch of chemistry dealing with the chemical and physico-chemical changes of solids due to the influence of mechanical energy.

Mechanochemistry is the science field that deals with athermal or ultra-fast chemical reactions between solids or between solids and surrounding gaseous or liquid molecules under mechanical forces. Another approach defines mechanochemistry as the branch of solid state chemistry where intramolecular bonds are mechanically broken [5]. Actually, the same is due to tribochemistry. Both mechanochemical and tribochemical reactions are also distinct from those of themochemical reactions. The same is due to heterogeneous catalysis (HetCat) and tribocatalysis [11]. Triboemission, triboplasma, and NIRAM-HSAB approach consider electronic effect of on mechanochemistry and tribochemistry. To initiate thermochemical reactions heat should be supplied. Thus, it seems convenient to consider heat evolution also in electronic terms. Additionally, it is suggested to consider tribochemistry as a subset of mechanochemistry.

There is an overlap of disciplines based on chemical reactions initiated by the mechanical action. Not considering any heat loss, the difference is controlled by energy stored in the system. Looking at the mechanical work plane proposed in [15], various portions of the work (power) include: input power, use-output power, loss-output energy rate, and a stored energy (thermal energy transformed from mechanical work). The energy stored (excess energy) serves as the origin of enhanced reactivity of solids.

\subsubsection{Differences between mechanochemistry and tribochemistry}

Taking into account that tribochemistry is the subset of mechanochemistry, major differences between mechanochemistry and tribochemistry is formal, as compared with chemical physics and physical chemistry. There are many physical processes related to the wearing and mechanisms. These mechanisms are often connected with tribochemical reactions. The nature of the tribochemical film is the key to understanding the mechanochemical processes that give rise to chemical films separating friction solid elements.

Significant evidence for the above suggestion comes from book [77]. That book aimed at correlating mechanical actions on organic substances with the molecular events triggert by these actions. The term organic mechanochemistry, defined as convertion of mechanical energy into the driving force for molecular oe structural phase trtansitions, was introduced. Importantly, Todres in his book [77] emphasizes that chemical engineering needed inorganic mechanochemistry be addressed first. Organic mechanochemistry has been in its infancy for a long time. The specificity of the Todres' book is that it discusses chemical reactivity of organic molecules mechanically treated separately or together and, describes 
mechanochemically initiated polymerization, depolymerization and mechanolysis. It also considers lubricant design and lubricity process and, differentiates mechanochemical publications from tribochemical ones.

At this point, it is proposed to assign inorganic mechanochemistry to mechanochemistry and, organic mechanochemistry to tribochemistry. Thus, major differences between mechanochemistry and tribochemistry have a formal character.

\subsubsection{Common denominators of mechanochemistry and tribochemistry}

Considering that the excess energy (energy stored in a sytem) serves as the origin of enhanced reactivity of materials under mechanical treating, their common denominators broadly encompass triboemission and triboplasma processes.

In the present Chapter understanding, there is only a formal overlap of these disciplines in terms of inorganic and organic chemistry. Accordingly, mechanochemistry is the inorganic mechanochemistry and, tribochemistry is the organic mechanochemistry. Tribochemistry is considered as a subset of mechanochemistry.

The major denominatot for inorganic mechanochemistry, organic mechanochemistry, catalysis and tribocatalysis is the NIRAM-HSAB approach, because it allows accounting for most of very specific tribological findings. It also demonstrates how organic chemistry is changing via physical chemistry, chemical physics and nowadays by contributing to tribochemistry. Book chapter [82] details physical and chemical phenomena concerning the tribochemistry discipline.

\section{Conclusions}

Mechanically initiated chemical reactions in solids are not new and presently there are many practical and theoretical achievements. Since mechanically initiated chemical reactions in solids have not received adequate attention yet, first of all a better understanding between researchers dealing with mechanochemistry and tribochemistry is needed. It was a major goal of this Chapter.

The new approach to mechanically initiated chemical reactions shows that the NIRAMHSAB theory is important in accounting for most of very specific tribological findings and, also allows to account for the first mechanochemical reactions, for example

$$
\mathrm{HgS}+\mathrm{Cu} \longrightarrow \mathrm{Hg}+\mathrm{CuS}
$$

or modify the mechanism of heterogeneous $\mathrm{C}-\mathrm{C}$ bond splitting in polymers.

\section{Author details}

Czesław Kajdas

Automotive Industry Institute PIMOT, Warsaw

Warsaw University of Technology, Institute of Chemistry, Płock, Poland 


\section{Acknowledgement}

The author wishes to acknowledge PIMOT for this project financial support and, Krzysztof Kowalczyk for his assistance in preparing figures.

\section{References}

[1] Carey-Lea M. On Endothermic Reactions Effected by Mechanical Force. Philosophical Magazine 1893, 36, 350-351.

[2] Takacs L. M. Carey Lea. The Father of Mechanochemistry. Bulletin for the History of Chemistry 2003, 28(1), 26-34.

[3] Takacs L. M. Carey Lea, the First Mechanochemists. Journal of Materials Science 2003, 39(16-17), 4987-4993. See also: Takacs L. The First Documented Mechanochemical Reaction? Journal of Metals 2000; (Jan issue) 12-13.

[4] Vick B., Furey M. J., Kajdas C. An Examination of Thermionic Emission Due to Frictionally Generated Temperatures, Tribology Letters 2002, 13(2), 147-153.

[5] Kaupp G, Waste-Free Synthesis and Production all Across Chemistry with the Benefit of Self- Assembled Crystal Packings. Journal of Physical Organic Chemistry 2008, 21(7-8), 630-643. ISSN: 08943230; DOI: 10.1002/poc.1340.

[6] Kaupp G. Mechanochemistry: the Varied Applications of Mechanical Bond-Breaking, The Royal Society of Chemistry, CrystEngComm 2009, 11, 388-403. DOI: 10.1039/b810822f ...

[7] Thiessen P.D., Meyer K., Heinicke G. Grundlagen der Tribochemie. Berlin: AkademieVerlag, 1966.

[8] Heinicke G. Tribochemistry. Berlin: Academy-Verlag, 1984.

[9] Hardy W. Collected Works. Cambridge: University Press, 1936.

[10] Campbell, W.F. Boundary Lubrication. In: Ling F.F., Klaus E.E., Fein R.S. (eds) Boundary Lubrication. An Appraisal of World Literature. New York: ASME; 1969.pp87117.

[11] Kajdas C., Hiratsuka K. Tribochemistry, Tribocatalysis, and the Negative-Ion-Radical Action Mechanism. Proceedings of the Institution of Mechanical Engineers Part J: Journal of Engineering Tribology 2009; 223 (6) 827-848. DOI: 10.1243/13506501JET514

[12] Bond G.C. Heterogeneous Catalysis. Principles and Applications. Oxford: Clarendon Press, 1987.

[13] Hsu S.M., Zhang J., Yin Z. The Nature and Origin of Tribochemistry. Tribology Letters 2002, 13(2) 131-139.

[14]http://books.google.pl/books?id=8lsEsGe18t8C\&pg=PA587\&lpg=PA587\&dq=definition+ of+tribochemistry\&source=bl\&ots=UFdquGVHoK\&sig=HQoet9rQjpUgUb7c0b97TzXHI $\mathrm{x} 8 \& \mathrm{hl}=\mathrm{pl} \& \mathrm{sa}=X \& \mathrm{ei}=\mathrm{WLy} X \mathrm{~T} 9 \mathrm{HJEsrf4QTDyqDFBg \& sqi}=2 \& \mathrm{ved}=0$ CDAQ6AEwAQ\# $\mathrm{v}=$ on epage\&q=definition $\% 20$ of $\% 20$ tribochemistry\&f $=$ false

[15] Czichos H. Tribology a Systems Approach to the Science and Technology of Friction, Lubrication and Wear. Amsterdam: Elsevier; 1978. 
[16] Butyagin P.Yu. Kinetics and Nature of Mechanochemical Reactions. Russian Chemical Reviews 1971, 140 (11) 901-915.

[17] Guha D, Roy Choudhuri S.K. The effect of surface roughness on the temperature at the contact between sliding bodies. Wear 1996, 197 (1-2) 63-73. DOI: 10.1016/j.bbr.2011.03.031

[18] Kajdas C., Harvey S.S.K., Wilusz E. Encyclopedia of Tribology. Amsterdam: Elsevier; 1990.

[19] Kalin M. Influence of Flash Temperatures on the Tribological Behavior in Low-Speed Sliding: a Review. Materials Science and Engineering A 374 (2004) 390-397. DOI:10.1016/j.msea.2004.03.031

[20] Weick BL, Furey MJ, Vick B. Surface Temperatures Generated with Ceramic Materials in Oscillating/Fretting Contact. Transactions of the ASME, Journal of Tribology 1994, 116 (4) 260-267.

[21] Archard JR. The Temperature of Rubbing Surfaces. Wear 1959, 2(6) 438-455.

[22] Archard JR., Rowntree RA. The Temperature of Rubbing bodies.Part 2. The Distributions of Temperatures. Wear 1988, 128(1) 1-17.

[23] Marscher WD. A Critical Evaluation of the Flash Temperature Concept. ASLE Transactions 1982, 25(2) 157-174. DOI: 10.1080/05698198208983077

[24] Blok H. Theoretical Study of Temperature Rises of Actual Contact under Oiliness Lubricating Conditions. Proceedings of General Discussion on Lubrication. London: Instn Mech Engr; 1937 vol. 2. p. 222-35.

[25] Blok H. The flash temperature concept. Wear 1963, 6(6) 483-494. DOI.org/10.1016/00431648(63)90283-7

[26] Archard JF. Contact and Rubbing of Flat Surfaces. Journal of Applied Physics 1953; 24:981-988.

[27] Carslaw HS, Jaeger JC. Conduction of heat in solids. Oxford: Oxford University Press; 1959.

[28] Soom A, Serpe CI, Dargush GF. Thermomechanics of Sliding Contact. Fundamentals of Tribology and Bridging the Gap between the Macro and Micro/Nanoscales. NATO Science Series. II. Mathematics, Physics and Chemistry, vol. 10. Dordrecht: Kluver; 2001 p. $467-85$.

[29] Kajdas CK. Importance of the Triboemission Process for Tribochemical Reaction. Tribology International 2005, 38 (3) 337-353. DOI:10.1016/j.triboint.2004.08.017

[30] Vick B, Furey MJ. A Basic Theoretical Study of the Temperature Rise in Sliding Contact with Multiple Contacts. Nordtrib' proceedings, vol. 2. Porvoo, Finland: VTT; 2000 p. 389-98.

[31] Vick B., Furey MJ, Foo SJ.Boundary Element Thermal Analysis of Sliding Contact. Numerical Heat Transfer, Part A: Applications: An International Journal of Computation and Methodology 1991, 20(1) 19-40. DOI:10.1080/10407789108944807

[32] Tagawa M., Mori M., Ohmae N., Umeno M., Takenobu S. Tribo- and Photo-Stimulated Exoelectron Emission from Graphite. Tribology International 1993, 26(1) 57-60. ISSN: 0301679X 
[33] Momose Y, Iwashita M. Surface Analysis of Metals using Tribostimulated Electron Emission. Surface and Interface Analysis 2004, 36(8) 1241-1245. DOI: 10.1002/sia.1885

[34] Nevschupa RA. Triboemission: An Attempt of Developing a Generalized Classification. In: Tribology Science and Application, Herman MA (Ed.), CUN PAN, Warsaw; 2004 p. $11-25$

[35] Nakayama K, Suzuki N, Hashimoto H. Triboemission of Charged Particles and Photons from Solid Surfaces during Frictional Damage. Journal of Physics D: Applied Physics 1992; 25(2) 303-308. DOI:10.1088/0022-3727/25/2/027

[36] Kim MW, Langford SC, Dickinson JT. Electron and Photon Emission Accompanying the Abrasion of $\mathrm{MgO}$ with Diamond. Tribology Letters 1 1995, 1(2-3) 147-157. DOI: 10.1007/BF00209770

[37] Molina GJ, Furey MJ, Ritter AL, Kajdas C. Triboemission from Alumina, Single Crystal Sapphire, and Aluminum. Wear 2001; 249(3-4) 214-219. PII: S0043-1648(01)00568-3

[38] Molina GJ, Furey MJ, Vick B, Ritter AL, Kajdas C. Triboemission from the Sliding Contact

of Alumina Systems. Proceedings of the Second World Tribology Congress, Vienna, Austria 2001.

[39] Molina GJ, Triboemission from Ceramics: Charge Intensity and Energy Distribution Characterizations. PhD Dissertation, Deptartment of Mechanical Engineering, Virginia Polytechnic Institute and State University, Blacksburg; 2000.

[40] Kajdas C. On a Negative-Ion Concept of EP Action of Organo-Sulfur Compounds. ASLE Transaction 1983; 28(1) 21-30.

[41] Sato N, Seo M. Chemically Stimulated Exo-Emission from a Silver Catalyst. Nature 1967; 216(Oct) 361-362. DOI:10.1038/216361a0

[42] Ramsey JA. The Emission of Electrons from Aluminum Abraded in Atmospheres of Air, Oxygen, Nitrogen and Water Vapor. Surface Science 1967, 8(3) 313-322. DOI.org/10.1016/0039-6028(67)90114-8

[43] Varentsov EA, Khrustalev YA. Mechanoemission and Mechanochemistry of Molecular Organic Crystals. Russian Chemical Reviews 1995; 64(8) 783-797. IOP.org/0036021X/64/8/R06

[44] Khrustalev YA. Electric Phenomena on the Rupturing of Adhesive Contact and Failure of Solids: Development Stages from Gas Discharge to Cold Nuclear Fusion. Colloids and Surfaces A: PhysicoChemical and Engineering Aspects 1993, 79(1) 51-63. DOI.org/10.1016/0927-7757(93)80159-C

[45]. Thiessen KP, Sieber K. Energetische Randbedingungen tribochemischer Prozesse. Teil 3. Chemie Leipzig 1979, 260(3) 410-416.

[46] Baláž P. Mechanochemistry in Nanoscience and Minerals Engineering. Berlin: SpringerVerlag,

2008.http://books.google.pl/books?id=FldqbSffUMgC\&pg=PA1\&lpg=PA1\&dq=Bal\%C3 $\% \mathrm{~A} 1 \% \mathrm{C} 5 \% \mathrm{BE}+\mathrm{P} .+$ Mechanochemistry+in+Nanoscience+and+Minerals+Engineering.+Ber lin:+Springer-Verlag, +2008

[47] Pawlak Z. Tribochemistry of Lubricating Oils. Amsterdam: Elsevier; 2003. 
[48] Tysoe TT, Kotvis PT. Surface Chemistry of Extreme Pressure Lubricant Addtitives. In Surface modification and mechanisms (Eds G. E. Totten and H. Liang), 2004, ch. 10, pp. 299-351 (Marcel Dekker, Inc., New York, Basel).

[49] Vižintin J. Additive Reaction Mechanisms. In Surface modification and mechanisms (Eds G. E. Totten and H. Liang), 2004, ch. 9, pp. 243-298. (Marcel Dekker, Inc., New York, Basel).

[50] Buyanovsky IA, Zimaida VI, Zaslavsky RN. Tribochemistry of Boundary Lubrication Processes. In Surface modification and mechanisms (Eds G. E. Totten and H. Liang), 2004, ch. 11, pp. 353-404. (Marcel Dekker, Inc., New York, Basel).

[51] Kajdas C. Tribochemistry. In Surface modification and mechanisms (Eds G. E. Totten and H. Liang), 2004, ch. 6, pp. 99-164. (Marcel Dekker, Inc., New York, Basel).

[52] M. Majzner, Kajdas C. Reactions of Carboxylic Acids under Boundary Friction Conditions. Tribologia 2003; 34(1) 63-80 (in Polish).

[53] Fischer DA, Hu ZS, Hsu SM. Tribochemical and Thermochemical Reactions of Stearic Acid on Copper Surfaces in Air as Measured by Ultrasoft X-Ray Absorption Spectroscopy.Tribology X-Ray Absorption Spectroscopy Tribology Letters 1997; 3(10) 35-40. DOI: 10.1023/A:1019109407863

[54] Makowska M, Kajdas C, Gradkowski M. Interactions of Hexadecane with 52100 Steel Surface under Friction Conditions. Tribology Letters 2002;13(2) 65-70.

http://www.ingentaconnect.com/content/klu/tril/2002/00000013/00000002/00377942

[55] Kajdas C, Shuga'a AK. Investigation of AW Properties and Tribochemical Reactions of Esters of Palmitic Acid and Aliphatic Alcohols in the Steel-on-Steel System. Tribologia 1998; 29(xx) 389-402 (in Polish).

[56] Kajdas C. Hydrolysis. In Surface modification and mechanisms (Eds G. E. Totten and H. Liang), 2004, ch. 8, pp. 203-241. (Marcel Dekker, Inc., New York, Basel).

[57] von Ardenne M, Steinfelder K, Tuemmler R. ElektronenanlagerungsMassenspektrographie organischer Substanzen. Berlin: Springer; 1971.

[58] Gilman JJ. Mechanochemistry. Science 1996; 274 (5284) $65 . \quad$ DOI: 10.1126/science.274.5284.65

[59] Burdett JK. Chemical Bonding in Solids. New York: Oxford University Press; 1995. http://books.google.pl/books/about/Chemical_Bonding_in_Solids.html?id=ZCOQENZVTIC\&redir_esc=y

[60] Dante RC, Kajdas CK. A Review and a Fundamental Theory of Silicon Nitride Tribochemistry. Wear 2012; 288(5) 27-38. http://dx.doi.org/10.1016/j.wear.2012.03.001

[61] Gates RS, Hsu SM. Boundary Lubrication of Silicon Nitride, National Institute of Standards and Technology (NIST) Special Publication 876. NIST, Gaithersburg, MD 20899-0001, USA, February 1995, pp. (i)-(xv) and 1-379.

[62] Gates RS, Hsu SM. Silicon Nitride Boundary Lubrication: Lubrication mechanism of Alcohols, Tribology Transactions 1995; 38(3) 645-653. ISSN 0569-8197

[63] Tsutsumi T, Hiratsuka K, Ohta K, Kajdas C. Activation Energy of Tribocatalysic Oxidation of Ethylene. P17 at the International Tribochemistry Conference Hagi, Japan 2012. 
[64] Molchanov VV, Buyanov RA. Mechanochemistry of Catalysts. Russian Chemical Reviews 2000; 69 (5) 435- 450. DOI 10.1070/RC2000v069n05ABEH000555

[65] Hill J. Theophrastus' History of Stones. London 1774; p. 235.

[66] Boldyrev VV, Tkacova K. Mechanochemistry of Solids: Past, Present, and Prospects. Journal of Materlials. Synthesis and Processing 2000; 8(3-4) 121-132.

[67] Chandra BP, Patel NL, Rahangdale SS, Patel RP, Patle VK. Characteristics of the Fast Electron Emission Produced During the Cleavage of Crystals. PRAMANA Journal of Physics. Indian Academy of Sciences 2003; 60(1) 109-122.

[68] Sakaguchi M, Miwa Y, Hara S, Sugino Y, Yamamoto K, Shimada S. Triboelectricity in Polymers: Effects of the Ionic Nature of Carbon-Carbon Bonds in the Polymer Main Chain on Charge due to Yield of Mechano-Anions Produced by Heterogeneous Scission of the Carbon-Carbon Bond by Mechanical Fracture. Journal of Electrostatics 2004; 62(1) 35-50. http://dx.doi.org/10.1016/j.elstat.2004.04.003

[69] O'Grade PF. Thales of Miletus: The Beginnings of Western Science and Philosophy. Aldershot, UK: Ashgate 2002.

[70] Lacks DJ, Sankaran RM. Contact Eectrification of Isulating Materials. Journal of Physics D: Applied Physics 2011; 44, 453001 (15pp), DOI:10.1088/0022-3727/44/45/453001

[71] INCOME Conference 2011: http://www.mrs-serbia.org.rs/income2011/income2011.html

[72] James SL et al. Mechanochemistry: Opportunities for New and Cleaner Synthesis. Chemical Society Reviews of the Royal Society of Chemistry 2012; 41, 413-447. DOI: 10.1039/c1cs15171a

[73] Beyer KB, Clausen-Schaumann H. Mechanochemistry: the Mechanical Activation of Covalent Bonds. Chemical Reviews 2005; 105(8) 2921-2948. DOI:10.1021/cr030697h

[74] Fujiwara K, Komatsu K. Mechanochemical Synthesis of a Novel C60 Dimer Connected by a Silicon Bridge and a Single Bond. Organic Letters 2002; 4(6) 1039-1041. DOI:10.1021/ol025630f.

[75] Guo X, Xiang D, Duan G, Mou P. A Review of Mechanochemistry Applications in Waste Management. Waste Management 2010; 30, 4-10.

[76] Andini S, Bolognese A, Formisano D, Manfra M, Montagnardo F, Santoro. L. Mechanochemistry of ibuprofen pharmaceutical. Chemosphere 2012: article in press; Available online 1 April 2012: http://dx.doi.org/10.1016/j.chemosphere.2012.03.025

[77] Todres ZV. Organic Mechanochemistry and its Practical Applications. Boca Raton: CRS Taylor \& Francis Group, LLC; 2006.

[78] Gutman EM. Mechanochemistry of Materials. Cambridge: Cambridge International Science Publishing; 1998.

[79] Baláž P. Extractive Metallurgy of Activated Minerals (Process Metallurgy). Amsterdam: Elsevier Science; 2000.

[80] Powder Technology Handbook. Masuda H, Higashitani K, Yoshida H, (eds). Boca Raton: CRS Taylor \& Francis Group, LLC; 2006.

[81] Bravi, M., Di Cave, S., Mazzarotta, B., Verdone, N. Relating the Attrition Behaviour of Crystals in a Stirred Vessel to their Mechanical Properties. Chemical Engineering Journal 2003; 94(3) 223-229. DOI:10.1016/S1385-8947(03)00053-67-353. 
[82] Kajdas C. Physical and chemical phenomena related to tribochemistry. In Advances in contact mechanics: Implications for materials science, engineering and biology. (Eds R. Buzio and U.Valbusa), 2006, ch. 12, pp. 383-412. (Transworld Research Network, Kerala, India). 